\title{
OTIMIZAÇÃO DAS CONDIÇÕES DE CULTURA PARA O CRESCIMENTO \\ BACTERIANO COMO PARA PRODUÇÃO DA DEXTRANA-SACARASE A \\ PARTIR DE Leuconostoc Pseudomesenteroides
}

\author{
Isabela Souza Coccorese ${ }^{1}$; Elinalva Maciel Paulo ${ }^{2}$; Claudio Roberto Nobrega \\ Amorim ${ }^{3}$ \\ 1. Bolsista PROBIC/UEFS, Graduando em Bacharelado em Ciências Biológicas, Universidade Estadual de Feira de \\ Santana, e-mail: isabelauefs@ hotmail.com \\ 2. Elinalva Maciel Paulo, Departamento de Ciências Biológicas, Universidade Estadual de Feira de Santana, e-mail: \\ elinalvamaciel@yahoo.com.br \\ 3. Claudio Roberto Nobrega Amorim, Departamento de Ciências Biológicas, Universidade Estadual de Feira de \\ Santana, e-mail: $\underline{\text { amorim@uefs.br }}$
}

PALAVRAS-CHAVE: Enzima; Dextrana Sacarase; Leuconostoc.

\section{INTRODUÇÃO}

Exopolissacarídeos de origem bacteriana têm despertado o interesse das mais variadas indústrias podendo ser utilizados para várias especialidades. A Dextrana é um dos exopolissacarídeos produzida por bactérias dos gêneros Leuconostoc, Lactobacillus e Streptococcus, pela ação da enzima Dextrana-Sacarase, que é ativada pela Sacarose (com exceção das espécies do gênero Streptococcus). A enzima utiliza a sacarose como substrato e polimeriza a dextrana. A Dextrana é um dos exopolissacarídeos de maior importância industrial, largamente utilizada como aditivo, espessante, estabilizante e emulsificante em produtos alimentícios, cosméticos, imobilizante em processos cromatográficos, e também na área médica, agindo como anticoagulante e extensor de plasma, dentre outros (Bhavani\&Nisha, 2010).

Muito empenho tem sido aplicado ao longo dos anos para desenvolver metodologias eficazes, rápidas e com menor custo para a produção das dextranas (Nigam et al., 2006); (Vettori et al., 2012). Assim, os estudos que se voltam para a Dextrana-Sacarase têm um papel fundamental neste processo. Dentre os benefícios desta abordagem, pode-se frisar a redução com gastos para manter a colônia, facilidade na separação final do produto com alto grau de pureza, além da possibilidade de reaproveitamento da enzima nas etapas da produção (Chiellini et al., 2001).

Dessa maneira, o presente estudo se justifica, portanto, em elaborar um método eficaz na produção Dextrana-Sacarase através das bactérias láticas produtoras de exopolissacarídeos isoladas da região, afim de verificar qual o melhor meio a ser utilizado e as condições mais favoráveis para que estas cresçam mais rapidamente consequentemente obtendo eficiência na obtenção do exopolissacarídeo de grande interesse industrial.

\section{MATERIAL E MÉTODOS OU METODOLOGIA (ou equivalente)}

Foram utilizadas neste trabalho amostras bacterianas de Leuconostooc pseudomesenteroides fornecidas pela Prof ${ }^{a}$. Dra. Elinalva Maciel Paulo, Coordenadora do LAMASP - Laboratório de Microbiologia Aplicada à Saúde Pública da Universidade 
Estadual de Feira de Santana (UEFS). Tais amostras foram triadas e isoladas conforme a metodologia descrita por PAULO et al. (2012), a partir de produtos alimentícios industrializados (laticínios) e vegetais. As amostras foram cultivas em treze meios diferentes testadas em diferentes $\mathrm{pH}(5,0 ; 5,5 ; 6,0 ; 6,5)$ e diferentes temperaturas $\left(25^{\circ} \mathrm{C}\right.$; $30^{\circ} \mathrm{C} ; 35^{\circ} \mathrm{C}$ ).

A atividade da enzima Dextrana-Sacarase foi detectada indiretamente, através da medição da taxa de produção do açúcar redutor D-Frutose a partir da Sacarose. O ensaio da dextrana foi realizado em $1 \mathrm{ml}$ de uma mistura de reação em tampão de acetato de sódio $20 \mathrm{mM}$, pH 5,4, contendo $146 \mathrm{mM}$ de sacarose (5\%) e utilizando o sobrenadante livre de células $(10$ a $20 \mu \mathrm{l})$ como fonte de enzimas. A mistura da reação foi incubada a $30^{\circ} \mathrm{C}$ durante $15 \mathrm{~min}$. A atividade enzimática foi mensurada através da estimativa do açúcar redutor libertado, pelo método do DNS (3,5 DinitroSalicilato). Alíquotas (0,2 $\mathrm{ml}$ ), a partir da mistura de reação foram analisadas para a concentração do açúcar redutor. A absorbância foi medida na faixa de $500 \mathrm{~nm}$, utilizando um espectrofotômetro de UV visível contra um padrão de D-frutose. 1 unidade (U) de atividade da DextranaSacarase definida será a quantidade de enzima que libera $1 \mu \mathrm{mol}$ de açúcar redutor por min a $30^{\circ} \mathrm{C}$ em tampão de acetato de sódio $20 \mathrm{mM}, \mathrm{pH}$ 5,4. O teor total da proteína do sobrenadante livre de células foi estimado pelo método de Lowry e colaboradores (1951), utilizando a albumina bovina sérica como padrão (SUMNER, 1935); (CONTIERO, 2004).

\section{RESULTADOS E/OU DISCUSSÃO (ou Análise e discussão dos resultados)}

A Tabela 1 mostra os resultados da análise da atividade enzimática utilizando-se o ácido 3,5-dinitrosalicílico (DNS) baseado no método de Miller (1959). As leituras foram efetuadas no espectrofotômetro UV/VIS modelo Varian, no comprimento de onda 595 $\mathrm{nm}$ obtendo os valores tabelados abaixo:

Tabela 1.Quantidade de enzima produzida a $25^{\circ} \mathrm{C}, 30^{\circ} \mathrm{C}$ e $35^{\circ} \mathrm{C}$, em U/ml

\begin{tabular}{|c|c|c|c|c|c|c|c|c|c|c|c|c|}
\hline & \multicolumn{3}{|c|}{ pH 5,0 } & \multicolumn{3}{|c|}{ pH 5,5 } & \multicolumn{3}{|c|}{$\mathrm{pH} 6,0$} & \multicolumn{3}{|c|}{ pH 6,5 } \\
\hline & $25^{\circ} \mathrm{C}$ & $30^{\circ} \mathrm{C}$ & $35^{\circ} \mathrm{C}$ & $25^{\circ} \mathrm{C}$ & $30^{\circ} \mathrm{C}$ & $35^{\circ} \mathrm{C}$ & $25^{\circ} \mathrm{C}$ & $30^{\circ} \mathrm{C}$ & $35^{\circ} \mathrm{C}$ & $25^{\circ} \mathrm{C}$ & $30^{\circ} \mathrm{C}$ & $35^{\circ} \mathrm{C}$ \\
\hline MEIO1 & 76,2 & 66,7 & 64,0 & 69,5 & 64,9 & 62,5 & 63,7 & 63,2 & 67,1 & 85,6 & 83,7 & 83,3 \\
\hline MEIO2 & 76,2 & 74,9 & 70,7 & 66,4 & 67,9 & 79,7 & 65,7 & 63,7 & 64,6 & 82,6 & 80,7 & 89,1 \\
\hline MEIO3 & 83,2 & 82,7 & 81,5 & 80 & 78,6 & 63,6 & 69,3 & 65,9 & 62,4 & 93,9 & 92,8 & 91,4 \\
\hline MEIO4 & 94,7 & 90,7 & 86,3 & 87,1 & 82,9 & 65,5 & 80,3 & 79,3 & 70,2 & 109,2 & 103,3 & 101,8 \\
\hline MEIO5 & 76,1 & 75,6 & 64,8 & 64,7 & 67,2 & 73,9 & 67,3 & 65,6 & 66,8 & 100,3 & 99,5 & 100 \\
\hline MEIO6 & 86,1 & 84,4 & 81,7 & 73,9 & 70,7 & 65,9 & 79,5 & 78,9 & 70,3 & 102,7 & 100,6 & 93,9 \\
\hline MEIO7 & 79,4 & 78,5 & 71,2 & 73,7 & 73,4 & 70,9 & 69,1 & 67,5 & 62,3 & 89,5 & 86,3 & 80,7 \\
\hline MEI08 & 87,6 & 86,4 & 83,5 & 81,4 & 82 & 81,7 & 64,8 & 63,6 & 64,6 & 97,3 & 90,6 & 85,5 \\
\hline MEIO9 & 70,7 & 68,6 & 64,9 & 65,3 & 66,4 & 66,8 & 63,7 & 63,1 & 62,2 & 97,4 & 95,7 & 90,4 \\
\hline
\end{tabular}




\begin{tabular}{ccccccccccccc} 
MEIO10 & 71,2 & 73,7 & 77,5 & 67,9 & 63,8 & 64,8 & 67,9 & 64,7 & 62,4 & 95,8 & 94,7 & 89,7 \\
MEIO11 & 71,7 & 69,2 & 68,2 & 71 & 70 & 71,9 & 70,8 & 68,4 & 64,8 & 97,3 & 96,8 & 93,1 \\
MEIO12 & 97,4 & 82,8 & 77,3 & 77,8 & 72,5 & 70,7 & 71,1 & 69,6 & 66,9 & 89,2 & 92,8 & 88,2 \\
MEIO13 & 89,6 & 84,7 & 88,4 & 72,6 & 72,6 & 78,3 & 67,9 & 66,4 & 65,2 & 91,5 & 94,9 & 90,3 \\
\hline
\end{tabular}

Baseado nos resultados obtidos as condições otimizadas para a atividade enzimática foram aquelas com $\mathrm{pH}$ corresponde a 6,5 em condições de temperatura a $25^{\circ} \mathrm{C}$ e as menos favoráveis com $\mathrm{pH} 6,0$ e temperatura a $35^{\circ} \mathrm{C}$.

A avaliação enzimática mostrou valores altos que variam entre 62,2 - 109,2 U.mg-1 que demonstram a grande expressão de dextrana-sacarase por L. pseudomesenteroides. Dentre os 13 meios avaliados, se pode observar o meio 4 que atingiu o número mais elevado de enzima produzida (109,2 U.mg-1) sob as condições de temperatura de $25^{\circ} \mathrm{C}$ e pH a 6,5. Em contrapartida, houve baixa produção enzimática no meio 9 (62,2 U.mg1) sob as condições de produção enzimática com temperatura de $35^{\circ} \mathrm{C}$ e com pH 6,0 .

A tendência de produção de dextrana-sacarase ocorre em valores de $\mathrm{pH}$ e temperatura mais baixos em comparação com a produção de dextrana com a enzima a partir de outras fontes como o trabalho de M. Nigam, A. Goyal, and S.S. Katiyar (2005). Resultados mais semelhantes foram encontrados em dextrana-sacarases de Weissella cibaria e L. mesenteroides NRRL B-650, que é utilizado respectivamente $\mathrm{pH}$ 6,9 e pH 7,0 e temperatura de $24{ }^{\circ} \mathrm{C}$ e $23{ }^{\circ} \mathrm{C}$.

\section{CONSIDERAÇÕES FINAIS (ou Conclusão)}

Baseado nos dados obtidos conclui-se que o meio 4 composto de 4,0 gramas de sacarose, 2,0 gramas de extrato de levedura, 0,001 gramas de $\mathrm{NaCl}, \mathrm{MnSO} 4$ e FeSO4, 0,002 gramas de $\mathrm{CaCl}$, 0,02 gramas de $\mathrm{MgSO} 4 \mathrm{e}$ 2,0 gramas de $\mathrm{KH} 2 \mathrm{PO} 4$ foi o melhor para a obtenção de uma elevada atividade enzimática, e as condições otimizadas para essa atividade foram aquelas que o $\mathrm{pH}$ corresponde a 6,5 em condições de temperatura de $25^{\circ} \mathrm{C}$.

\section{REFERÊNCIAS}

BHAVANI, A.LAKSHMI; NISHA, J. Dextran - The Polysaccharide With Versatile Uses. International Journal Of Pharma And Bio Sciences. 2010.

BRADFORD, Marion M. A rapid and sensitive method for the quantitation of microgram quantities of protein utilizing the principle of protein-dye binding. Analytical biochemistry, v. 72, n. 1-2, p. 248-254, 1976.

CHIELLINI, EMO ET AL. Biomedical Polymers: Sustainable Polymer Science And Technology. ISBN 0-306-46652-X. 2001.

CONTIERO, J. Estudo Da Produção De Dextranasacarase Por Leuconostoc MesenteroidesFt 045 B, Tese de doutorado.Universidade Estadual Júlio de Mesquita Filho, Rio Claro - São Paulo. 2004. 
LOWRY, Oliver H. et al. Protein measurement with the Folin phenol reagent. Journal of biological chemistry, v. 193, n. 1, p. 265-275, 1951.

MILLER, Gail Lorenz. Use of dinitrosalicylic acid reagent for determination of reducing sugar. Analytical chemistry, v. 31, n. 3, p. 426-428, 1959.

NIGAM, M.; GOYAL, A.; KATIYAR, S.S. High Yield Purification Of Dextransucrase From LeuconostocMesenteroidesNrrl B-512f By Phase Partitioning .2005 .

PAULO, Elinalva Maciel et al. An alternative method for screening lactic acid bacteria for the production of exopolysaccharides with rapid confirmation. Food Science and Technology (Campinas), v. 32, n. 4, p. 710-714, 2012.

SUMNER, James B.; HOWELL, Stacey F. A method for determination of saccharase activity. Journal of Biological Chemistry, v. 108, n. 1, p. 51-54, 1935.

VETTORI ET AL. Dextran: Effect Of Process Parameters On Production, Purification And Molecular Weight And Recent Applications. Diálogos\&Ciência. 31, 171-186. 2012. 